\title{
NON-ASBESTOS INSULATION TESTING USING A PLASMA TORCH
}

\author{
R. E. Morgan, A. S. Prince, and S. A. Selvidge, Thiokol Propulsion, \\ Science and Engineering Huntsville Operations, Brigham Cin. Utah \\ and \\ J. Phelps, C. L. Martin, and T. W. Lawrence, National Aeronautics and Space Administration \\ Marshall Space Flight Center, Huntsville, Alabama
}

\section{Abstract}

Insulation obsolescence issues are a major concern for the Reusable Solid Rocket Motor (RSRM). As old sources of raw materials disappear, new sources must be found and qualified. No simple, inexpensive test presently exists for predicting the erosion performance of a candidate insulation in the full-scale motor. Large motor tests cost millions of dollars and therefore can only be used on a few very select candidates. There is a need for a simple, low cost method of screening insulation performance that can simulate some of the different erosion environments found in the RSRM.

This paper describes a series of erosion tests on two different non-asbestos insulation formulations, a KEVLAR@ fiber-filled and a carbon fiber-filled insulation containing Ethylene-Propylene-Diene Monomer (EPDM) rubber as the binder. The test instrument was a plasma torch device. The two main variables investigated were heat flux and alumina particle impingement concentration. Statistical analysis revealed that the two different formulations had very different responses to the main variables. The results of this work indicate that there may be fundamental differences in how these insulation formulations perform in the motor operating environment. The plasma torch appears to offer a low-cost means of obtaining a fundamental understanding of insulation response to critical factors in a series of statistically designed experiments.

\section{Introduction}

The RSRM has been in production for more than twenty years and will be in production for at least ten more years. Over such a long system life, it is difficuit to maintain a constant desigñ as some sutosystem suppliers have product changes or phase-outs.

Copyright @2000 Thiokol Propulsion, a division of Cordant Technologies, Inc. Published by American Institute of Aeronautics and Astronautics, Inc. with permission.
Considerable resources are being focused by NASA on finding and qualifying adequate replacements for materials that are no longer commercially available. NASA has spent $\$ 8.76$ million on an EPDM insulation reformulation plan and \$22.6 on an asbestos-free insulation plan to date.

The internal insulation in the RSRM plays a critical role in protecting the motor case from the harsh thermal environment in the motor which can exceed $5000^{\circ} \mathrm{F}$. Failure of the insulation to protect the case could result in catastrophic destruction and potentially, even loss of life. Because of the crucial nature of the role the insulation plays in the RSRM, extreme effort is made in selecting and verifying the safety margins for new formulations.

Typical insulation formulations contain as many as a dozen different specialty chemicals and the obsolescence of one of these materials requires a reformulation and re-qualification effort. Current reformulation efforts are focussing on an EPDM binder with a filler such as KEVLAR ${ }^{\circledR}$ fibers or carbon fibers. These fillers are being used as an environmentally acceptable substitute for asbestos. While asbestos is an excellent filler from a performance standpoint, health and environmental issues dictate its minimization.

The costs to test and qualify these new formulations are considerable for two main reasons. First there exists no simple, relatively inexpensive, sub-scale test vehicle that adequately simulates the erosion environment in the RSRM. Secondly, there appears to be more than one erosion mechanism at work in the RSRM because the iocation in the motô can vastly affect the erosion performance of a material. It should be noted that the static test motors have more erosion than the flight motors, indicating that gravity, acceleration, orientation, or other parameters play a role in the erosion scenario. 
Figure 1 (last page) compares the material decomposition or erosion rate of some candidate insulation formulations in full-scale RSRM test motors. In the cylindrical portion of the motor, the erosion rates appear to be comparable. In the aft dome area, the carbon fiber-filled insulation is a much better performer than the KEVLAR ${ }^{\circledR}$ fiberfilled insulation. This poor performance of the KEVLAR $\otimes$ fiber-filled insulation was not predicted by any sub-scale motor tests. The RSRM aft dome environment is particularly harsh and the exact cause is not understood. It is theorized that molten aluminum oxide, or alumina as it is commonly called, plays a key roll in the erosion mechanism at this location. Clearly there is a need for a small-scale test bed that can be used to determine the response function of insulation to specific variables in a welldesigned experiment. The resulting fundamental understanding would greatly benefit both insulation formulators as well as users. The plasma torch has a great potential for fulfilling this role.

\section{Technical Discussion}

The details of the plasma torch test-bed, the insulation test matrix, and discussion of the test results are considered in this section.

\section{Plasma Torch Test-Bed}

The plasma torch test bed was established at the Marshall Space Flight Center in 1986 as a means of testing ablative materials for use in nozzle applications. The initial success in testing nozzle materials lead to its consideration as a test vehicle for internal case insulation materials'.

Figure 2 (last page) shows the plasma torch configuration that was used in the subsequent insulation testing. The 7MB Metco Plasma Torch is shown attached to a mechanical beam or arm. Immediately to the left of the 2 -inch square insulation sample, is a heat flux gauge that is used to calibrate the torch on each test. A water spray fume hood operates in the test bay to trap any noxious gases produced as a result of the test. A particle feeder manufactured by Metco can be used to meter a powder into the gas stream. An electric arc of corsiani watiage (40 Kilowatis; is used to ireat a stream of $80 \%$ nitrogen and $20 \%$ argon to a temperature in excess of $10,000^{\circ} \mathrm{R}$.

The range of heat fluxes that can be accurately reproduced is $200 \mathrm{BTU} / \mathrm{ft}^{2} \mathrm{sec}$ to over 1200 $\mathrm{BTU} / \mathrm{ft}^{2} \mathrm{sec}$. The amount of powder that can be reproducibly fed into the gas stream ranges from 1 gram per minute to over a one hundred grams per minute.

A typical test consists of the following actions:

1. The insulation sample is weighed and the thickness measured. The sample is then placed in the sample holder

2. The heat flux gauge and the specimen are set at an equal distance from the plasma torch in the plane of the plasma torch movement.

3. The torch is moved to a neutral station and the torch is ignited. If particles are part of the test, the particle feeder is started.

4. The arm moves the torch to a predetermined spot over the heat flux gauge for approximately 2 seconds. If the reading is at the desired heat flux, then the torch is moved to the sample. If the flux is too high or too low the distance from the gauge is adjusted and the flux is measured again. This is repeated until the flux is within the desired tolerance.

5. The plasma torch is moved to the specimen and allowed to dwell there for 20 seconds.

6. The gun is extinguished and the gas is allowed to purge the specimen surface for 20 seconds.

7. The sample is weighed and measured for erosion. The char layer is then removed and the thickness measured again for char-affected depth.

8. The torch is inspected after every third test and parts such as the nozzle are replaced as needed.

\section{Material Test Matrix}

Four different EPDM-based insulation formulations were tested, a $2 \%$ KEVLAR®, a $7 \%$ KEYLARG an $11 \%$ KEYLARA, and a carbon fiber-filled version. The samples were 2.0 inch by 2.0 inch by $1 / 2$-inch coupons bonded to an aluminum plate. Three heat flux levels and three alumina flux rates were selected. These ranges were estimated to span the actual conditions present in the chamber of the RSRM. The 
particle size of the alumina was 17 to 21 micrometers. This size was chosen to match the calculated momentum of the alumina present in the combustion chamber of the RSRM at the aft dome, which was projected to be 60 feet per second for 100 micrometer particles. Table 1 shows the 2 factor, 3 level, statistical design matrix used for these tests. The materials, with two additional replicates, were all tested per the matrix in a random order.

\begin{tabular}{|c|c|c|}
\hline Test Number & $\begin{array}{c}\text { Heat Flux } \\
\text { Btu/ } \mathrm{ft}^{2} \mathrm{sec}\end{array}$ & $\begin{array}{c}\text { Alumina\% by } \\
\text { weight }\end{array}$ \\
\hline 1 & 300 & 0.0 \\
\hline 2 & 300 & 1.8 \\
\hline 3 & 300 & 3.6 \\
\hline 4 & 600 & 0.0 \\
\hline 5 & 600 & 1.8 \\
\hline 6 & 600 & 3.6 \\
\hline 7 & 900 & 0.0 \\
\hline 8 & 900 & 1.8 \\
\hline 9 & 900 & 3.6 \\
\hline
\end{tabular}

Table 1 Statistical Design Test Matrix for Insulation

\section{Discussion of Test Results}

For the sake of brevity, only the $11 \%$ KEVLAR@ fiber-filled (KFEPDM) and the carbon fiber-filled (CFEPDM) data will be presented. Both the $7 \%$ and the $11 \%$ KFEPDM have response surfaces that are fundamentally alike. The $11 \% \mathrm{KFEPDM}$ and CFEPDM were both considered the top candidates for the replacement of the asbestos containing insulation used in the aft dome of RSRM.

The erosion in the samples is defined as the erosion depth plus char thickness or equivalently the material affected depth to virgin material. The post-test measurements were reported as deviations from the measured thickness of the sample before testing. A negative number indicates a loss of material and a positive number indicates material swelling.
CFEPDM Results

Standardized Pareto Chart for erosionrate

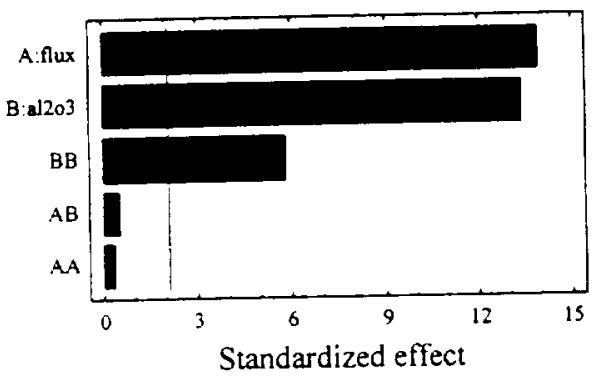

Estimated Response Surface

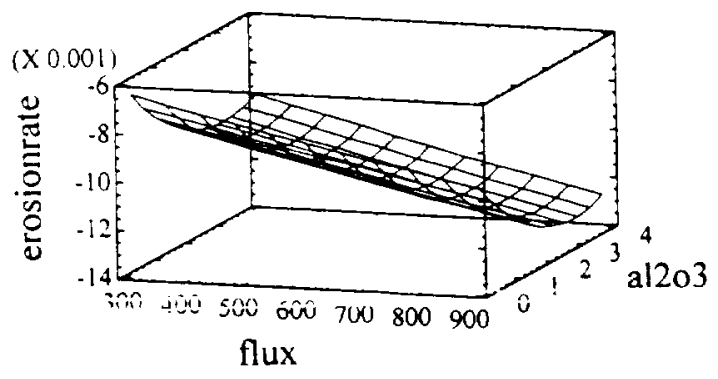

KFEPDM Results

Standardized Pareto Chart for erosionrate

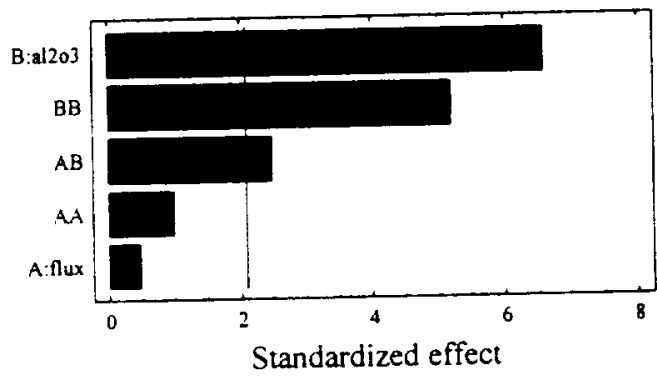

Estimated Response Surface

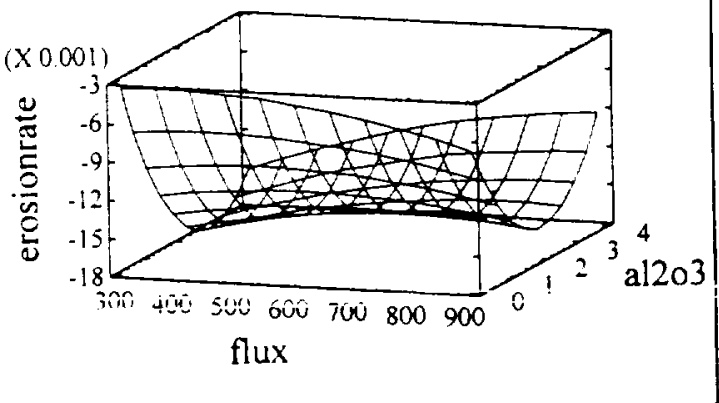

Figure 3 Erosion Rate Comparison of CFEPDM and KFEPDM 


\section{Erosion Rate}

A comparison of CFEDPM and KFEPDM erosion rate responses to heat flux and alumina levels is presented in Figure 3. As can be seen from the standardized Pareto charts, erosion rates of the two materials are affected by heat flux and alumina levels in dramatically different ways. CFEPDM is strongly and linearly affected by heat flux level and nonlinearly affected by alumina level. KFEPDM is highly and nonlinearly affected by alumina level and to a lesser extent by the flux and alumina interaction. Heat flux has an insignificant effect. The results are very informative and provide an explanation for the results obtained from the RSRM aft dome insulation erosion measurements.

By comparison with Figure 1, it appears that the erosion rate for CFEPDM at a heat flux of $300 \mathrm{BTU} / \mathrm{ft}^{2} \mathrm{sec}$ and alumina level of $1.8 \%$ corresponds to the erosion rate at the aft dome in RSRM. Under these conditions, the KFEPDM is at its highest erosion rate, as indicated by the data from the plasma torch. This vividly illustrates how the two formulations can have such different responses in the same environment.
CFEPDM Results

Standardized Pareto Chart for char

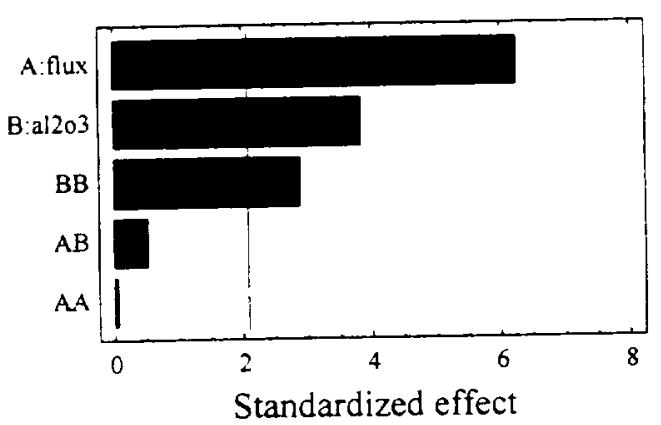

Estimated Response Surface

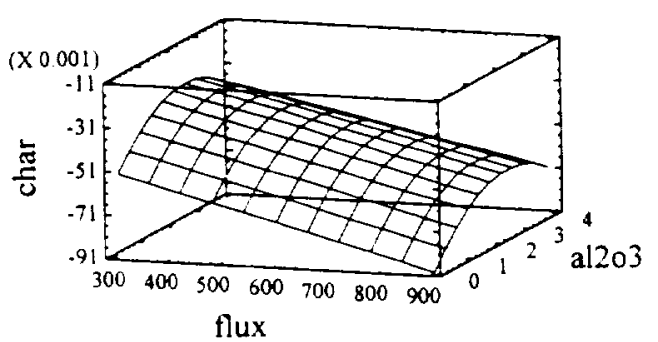

KFEPDM Results

Standardized Pareto Chart for char

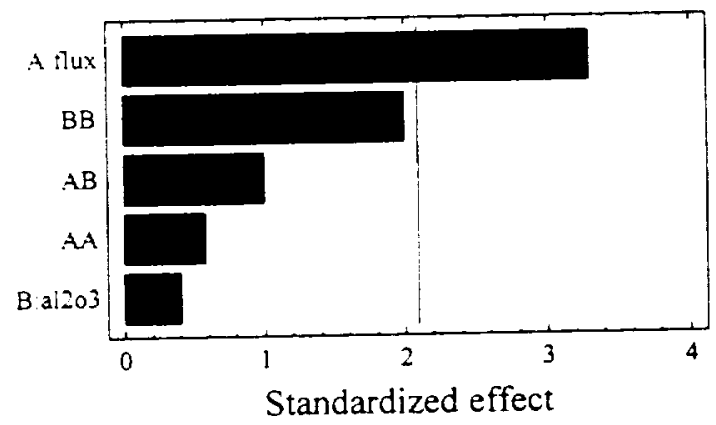

Estimated Response Surface

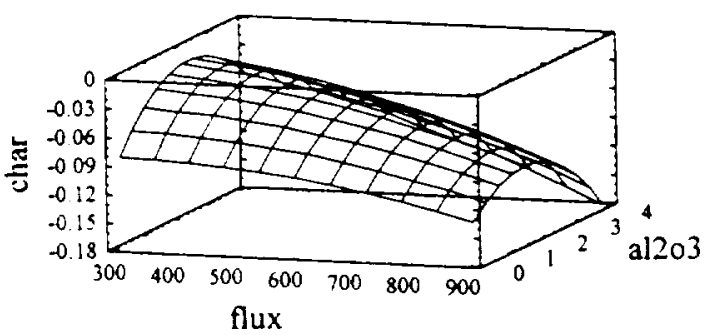

Figure 4 Char Depth Comparison of CFEPDM and KFEPDM 


\section{Char Depth}

The results in Figure 4 indicate the relationship of the insulation char depth to the factors of heat flux and alumina level. As the Pareto charts show, the primary driver is the linear effect of heat flux.

For CFEPDM the linear and quadratic effects of alumina level are also found to be significant. The response plots show the non-linearity associated with alumina levels. Char depths of both materials are lowest at low flux levels and at $1.8 \%$ alumina levels. KFEPDM has nearly twice the char depth of CFEPDM at the $0 \%$ alumina level. This thick char layer at low alumina levels may explain KFEPDM's high resistance to erosion at low alumina exposures. At low heat flux levels and at $1.8 \%$ alumina levels, the KFEPDM appears to lose the protection provided by a thick char layer and erosion rates become very high as shown in Figure 3.
CFEPDM Results

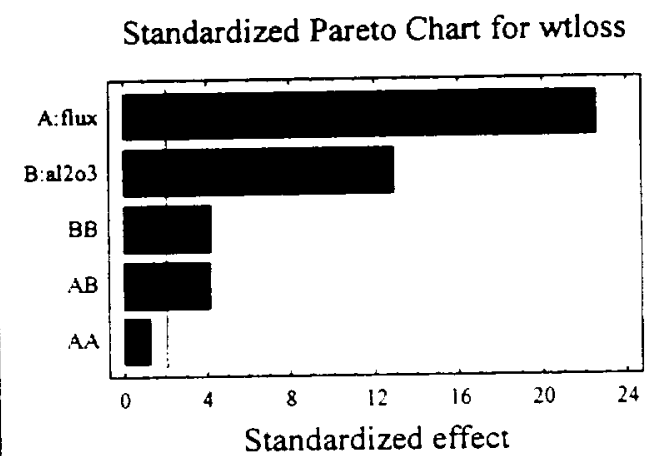

Estimated Response Surface

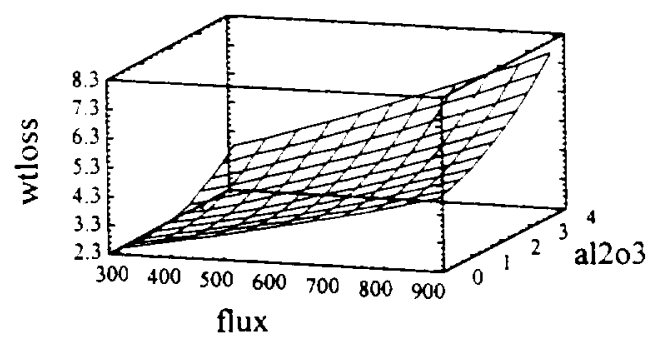

KFEPDM Results

Standardized Pareto Chart for wtloss

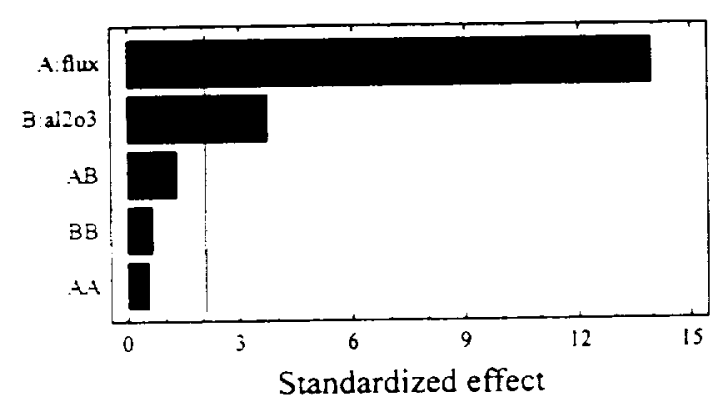

Estimated Response Surface

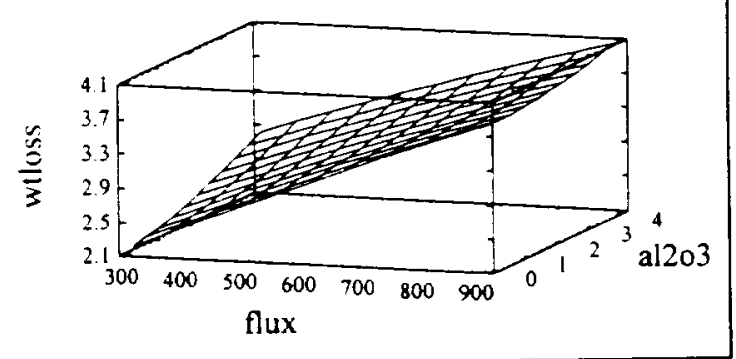

Figure 5 Weight Loss Comparison of CFEPDM and KFEPDM

\section{Weight Loss}

A comparison of CFEDPM and KFEPDM weight loss responses is shown in Figure 5. The Pareto charts indicate that the primary drivers are both the linear effects of heat flux and alumina level for both materials. The CFEPDM is also affected. albeit, by a lesser extent, by the nonlinear contribution of the alumina level and the interaction of the heat flux and alumina level.
As can be seen from the response surface plots, weight losses for the two materials is about the same at the $300 \mathrm{BTU} / \mathrm{ft}^{2} \mathrm{sec}$ heat flux and $0 \%$ alumina leve!s, but weight loss of CFEPDM is about twice as high for KFEPDM at the 900 $\mathrm{BTU} / \mathrm{ft}^{2} \mathrm{sec}$ heat flux and $3.8 \%$ alumina levels. An interesting observation is that weight losses are highest at the highest heat flux and alumina levels, but erosion rates are not. This would suggest that the material left after char removal 
is not "virgin" material. Material swelling, especially for KEVLAR\& fiber-filled materials, is another indication of changes in the remaining material. Because remaining material characteristics appear to be changing with time, initial and final remaining material densities should be recorded and erosion rates as a function of time should be established.

\section{Conclusions}

There is a need 1) to develop a fundamental understanding of how internal insulation formulations behave subject to the complex environment of a rocket motor combustion chamber and 2) for a small test device capable of providing this understanding at an affordable cost. It has been shown how a device based on a commercially available plasma torch can be used in the context of statistically designed experiments to meet this need.

It was shown that the erosion rate of CFEPDM and KFEPDM are affected by the two variables in distinctly different manners. CFEPDM erosion rate is more sensitive to heat flux than alumina level. KFEPDM erosion rate is sensitive to alumina concentration and insensitive to heat flux. This is the first time that this phenomenon has been observed in a sub-scale erosion test.

\section{Recommendations for Further Work}

As with all good experiments, more questions have been raised than answered. There is concern that insufficient melting of the alumina by the plasma torch may cause the large nonlinear effects at the highest level of alumina. The weight loss response surface, Figure 5, suggests that at the highest aluminum level, the plasma torch is transferring the greatest heat to the sample because the weight loss is the highest at this point. The erosion rate and char thickness response surfaces, Figures 3 and 4 , however, suggest the chemical reaction between the char and alumina is no longer occurring because the erosion rates and char thickness are near the values for the $0 \%$ alumina levels. These issues need to be investigated.
Chiba's paper ${ }^{2}$ indicates that chemical and mechanical erosion, in addition to particle size, velocity, and temperature, are important variables. Further work will involve the separation of the effect of mechanical erosion from chemical erosion through the use of statistically designed experiments. As a prelude to this effort, the particle feeder is being replaced with a newer model that will give more reproducible results. An inert curtain of gas will also be installed to prevent the entrainment of air into the sample area. This will allow the use of carbon as a feed particle for the mechanical verses chemical erosion tests without concern of it being consumed upon impingement on the sample.

A device capable of measuring the particle size distribution, velocity and temperature will also be purchased and mated to the system. This will allow more information to be gathered about the test environment.

\section{Acknowledgements}

Mr. Jimmy Belue is acknowledged for his work in preparing and testing all of the samples in addition to maintaining the plasma torch testbed in excellent working order. Mr. Robert Bunker kindly supplied the authors with a copy of Chiba's paper and made them aware of the effects of chemical erosion on nozzles.

\section{References}

1. Prince, A. S., "Final Test Report for ETP-7008, Non-Asbestos Insulation Abrasion Impingement", TWR-72008, Thiokol Propulsion, March 1997

2. Chiba, Z., "Particulate Impact Erosion In Entrance-Throat Region Of Solid Rocket Nozzles", CPIA Pub. 340, Vol. 1, pg. 175-187, JANNAF Propulsion Meeting, New Orleans, 1981 


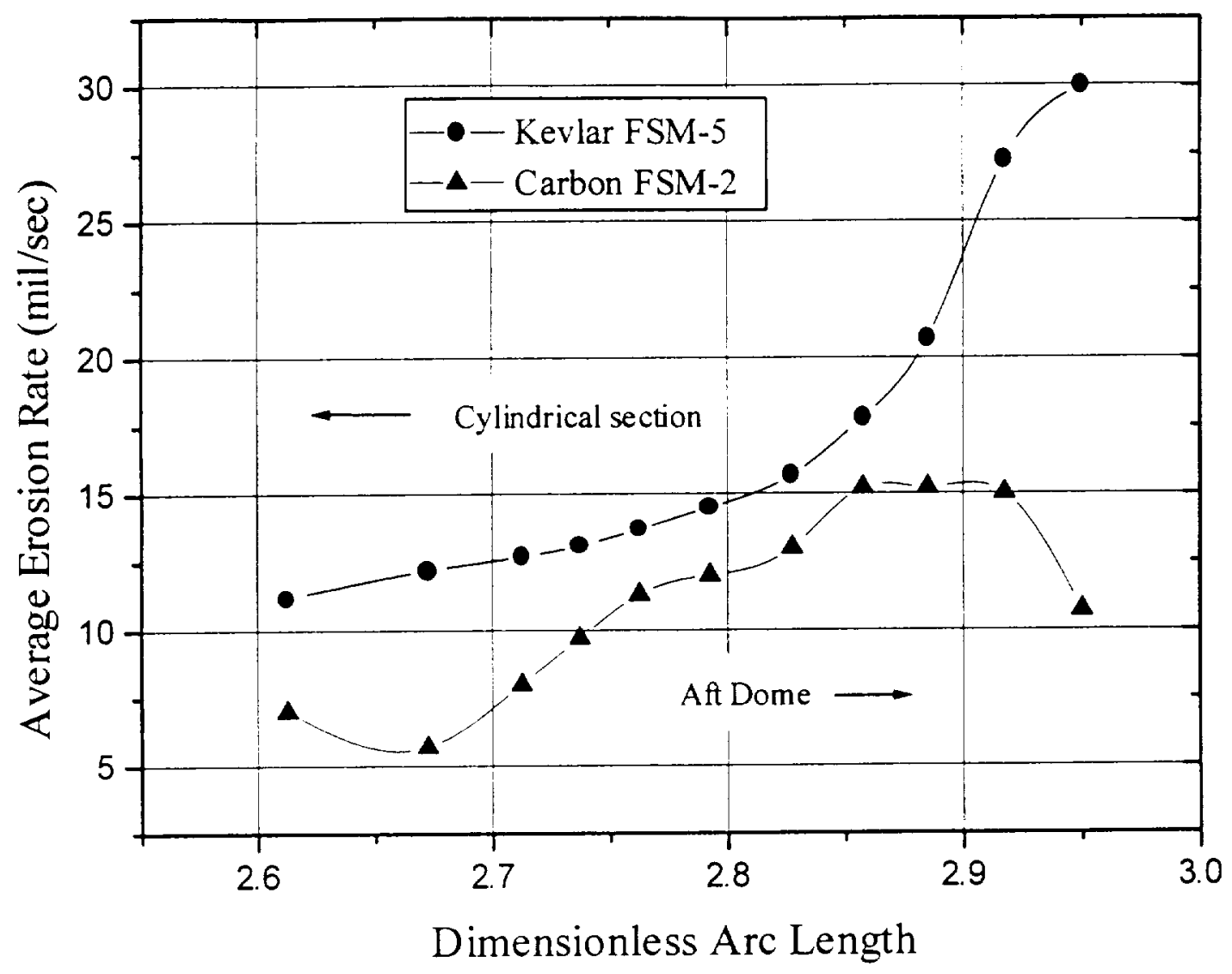

Figure 1 - Material Erosion Rates in RSRM Motors

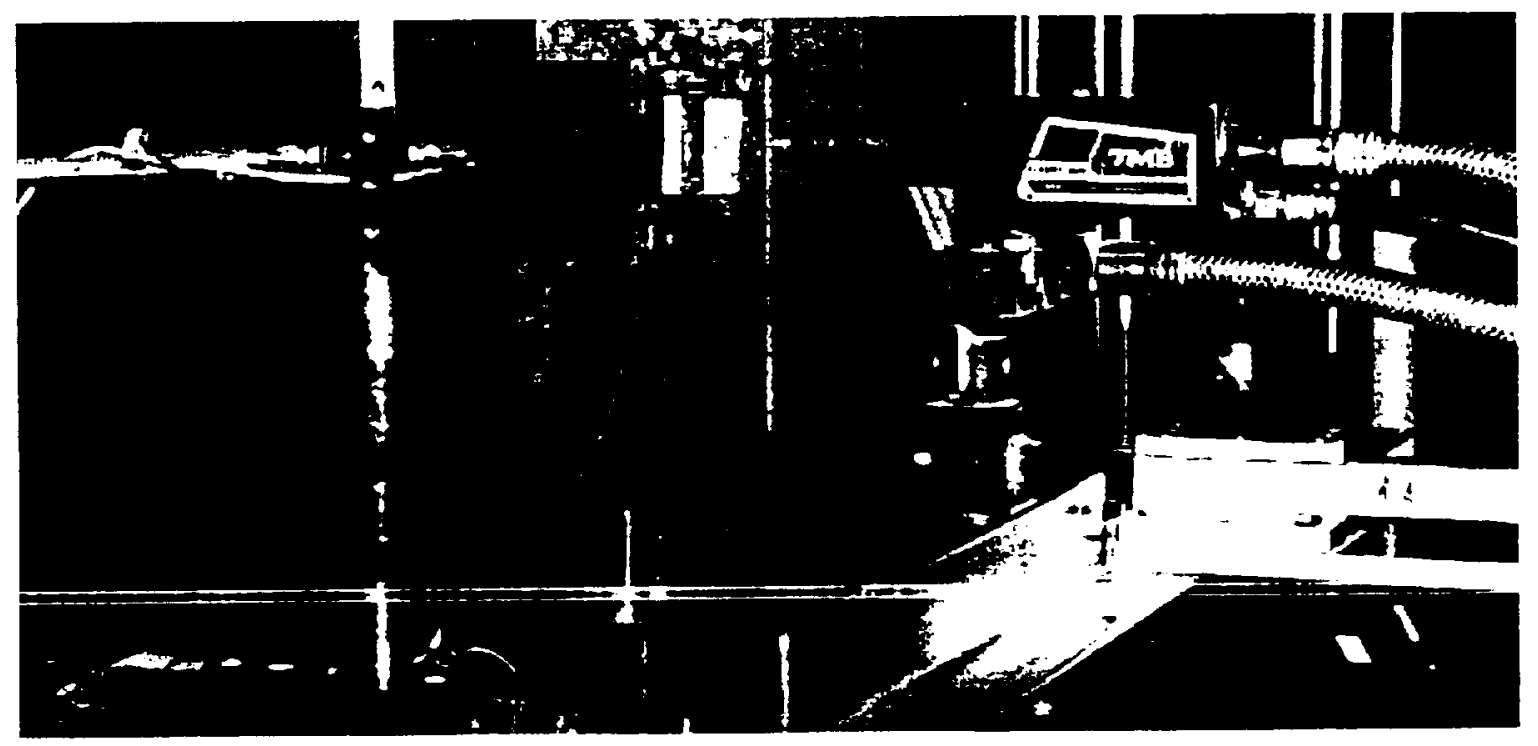

Figure 2 - Plasma Torch as Configured for Insulation Testing 